\title{
Identification of Chrysanthemum Flower Based on Color and Flower Form using Sobel Edge and Artificial Neural Network
}

\author{
Arie Qur'ania, Prihastuti Harsani, Veni Kertayu Putri
}

\begin{abstract}
Chrysanthemum is a popular ornamental plant in Indonesia because it has a variety of shapes and colors that attract a lot of attention. In addition to the trimmer, this flower can be used as a mosquito repellent and also absorbs dirty air pollution. Chrysanthemum flowers can be distinguished by color and shape with two types of ways to grow Chrysanthemum flowers that grow in clusters are called spray and also flowers that grow with no cluster or a flower per stalk. In addition, Chrysanthemum flowers have various color variations including pink, purple, yellow, white, orange, and red. The purpose of this study is to identify the type of Chrysanthemum flowers using extraction of Red, Green, Blue (RGB) color features and characteristic extraction using a Sobel edge detection, for his identification method using Artificial Neural Networks. Chrysanthemum data are white puma, Vania, Iranian, purple aster, and pink standard used in this research consisted of 100 training data and 50 tests data. The test was done with four tests that is identification with form extraction (Sobel) yielded accuracy value equal to $59.52 \%$, identification with color and shape extraction yield accuracy value equal to $65.36 \%$, identification with color extraction on flower and base flower plate yield value accuracy of $69.44 \%$, and identification with color extraction yields an accuracy value of $75.35 \%$.
\end{abstract}

Index Terms: Identify Chrysanthemum, Sobel, Artificial Neural Network.

\section{INTRODUCTION}

Chrysanthemum is a popular ornamental plant in Indonesia because it has a variety of shapes and colors that attract a lot of attention. In addition to the trimmer, this flower can be used as a mosquito repellent and also absorbs dirty air pollution [11][12]. Chrysanthemum varieties can be distinguished by the shape of flowers and colors, in this study used 5 varieties of chrysanthemum i.e. white puma, Vania, Iranian, purple aster, and pink standard. The method used in the identification of chrysanthemum flowers is an artificial neural network with input in the form of extraction of Red, Green, Blue (RGB) and edge shape extraction using Sobel. Train data consisted of 20 images for each variety and the test data consisted of 10 images of each variety.

Research using artificial neural network conducted by Agmalaro et al [1] to classify the surface of tropical fruit leaves based on the texture pattern of tropical fruit plants. The highest accuracy of this study after averaging is found in star fruit with an accuracy of $94 \%$. The lowest accuracy was found in jackfruit with an average accuracy of $66 \%$. Overall

Revised Manuscript Received on April 25, 2019.

Arie Qur'ania, Department of Computer Science, Pakuan University, Indonesia.

Prihastuti Harsani, Department of Computer Science, Pakuan University, Indonesia.

Veni Kertayu Putri, Department of Computer Science, Pakuan University, Indonesia. test results for tropical fruit plants with 7 hiddenneurons produce the best accuracy of $90 \%$.Research using an artificial neural network with the object of interest done by Siraj et al [13]. This study aims to classify 10 different types of flowers. For the results of the study by ignoring the color of flowers, flowers Allamanda, Rose, and Arcturus have a value of training accuracy of $60 \%$. After more flowers were drawn for each flower, the highest accuracy value of the training was obtained by Allamanda with $100 \%$ accuracy, $69 \%$ Rose, and Arcturus $100 \%$. This study shows that the number of images produced affects the accuracy of the results of the training.

Research using sobel edge detection to identify jasmine flowers was done by Qur'ania and Sarinah [10]. Testing the size of a jasmine flower image that is $50 \times 50$ pixels, $100 \times$ 100 pixels, $150 \times 150$ pixels produces an accuracy of $84 \%$. Tests on distance values from the k-NN method with a distance of 5,10 and 15 produce the highest accuracy rate of $84 \%$, and the smallest accuracy is $65.2 \%$.

The research for the classification of Japanese, Cambodian flower (Adenium sp.) Based on the crown image using color feature extraction and edge detection was done by Ichsani et al [5]. Data using 7 types of flowers Adenium sp. Each of which used 3 test samples resulting in 21 tests, plus 4 samples of the Adeniumsp flower test. Percentage of system success got value equal to $96 \%$ with failure percentage equal to $4 \%$. As for the percentage of success of the classification of flowers type Adenium sp. From 25 tests, 24 successful tests were obtained. Based on the combined feature with the highest hue histogram resemblance value as a reference is $25 \%$. The similarity value of the result of detection of the edge of Sobel as reference gets the biggest value that is $33.33 \%$. The hue resemblance of hue histogram $=$ highest similarity value of detection of the highest edge of the hence obtained a percentage value of $41.67 \%$.

Chrysanthemum flowers can be distinguished by color and shape. There are two types of ways to grow chrysanthemum flowers that grow in clusters or called spray and also flowers that grow with no cluster or a flower per stalk. In addition, chrysanthemum flowers have various color variations including pink, purple, yellow, white, orange, and red. Based on previous research, an application of chrysanthemum flower identification using an artificial neural network with color feature extraction and flower shape and flower plate as the unique differentiator of each chrysanthemum varieties. 


\section{Identification of Chrysanthemum Flower Based on Color and Flower Form Using Sobel Edge and ArtificialNeuralNetwork}

\section{METHODOLOGY}

Digital data in the form of images or images processed through several stages [6] so that computers can finally recognize the type of chrysanthemum flowers through digital data. The image is inputted through the preprocessing stage before the image is done crop stage and resizes [8]. The preprocessing stage is very important to do because the new image can be processed to the next stage after going through this stage. Furthermore, the image that has been through the preprocessing stage extraction of color and shape features [9]. The color feature extraction used is the extraction of RGB (Red, Green, Blue) features while the extraction of the shapes uses the edge detection of a sobel. The RGB color feature extraction aims to get the RGB value of interest. Form extraction using edge detection sobel aims to get the edge of the flower so that the resulting value of 1 and 0 which means 1 is the edge of interest while 0 is the background of the image. After the stages are passed, then the image is identified by using an artificial neural network.

The characteristic extraction used to identify this chrysanthemum flower is RGB color extraction (Red, Green, Blue) and shape extraction with edge detection. RGB color feature extraction is used because the color of the five types of chrysanthemum flowers have a variety of colors and some are almost the same so that the RGB color must be extracted so that the value obtained from RGB in order to be a differentiator of the type of flower that one with other flowers. The extraction of the form by using the edge detection of a sobel is done because the type of interest identified has a different shape. The stage to be performed by the system can be seen in Fig. 1.

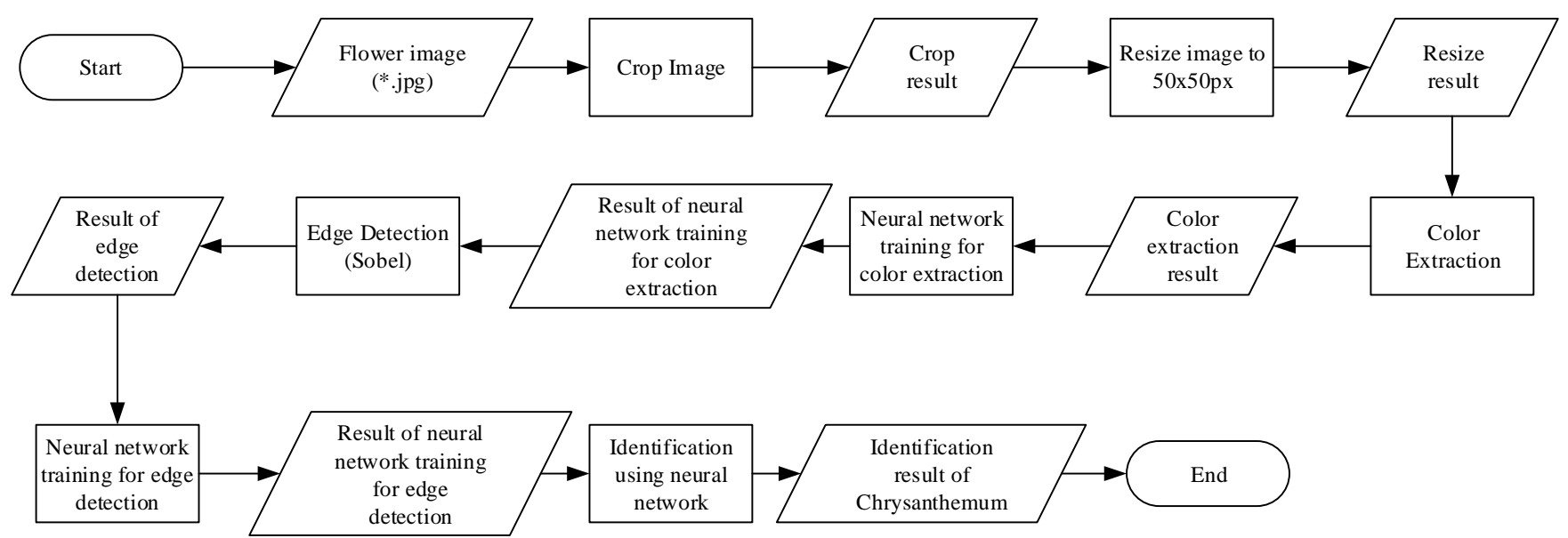

Fig. 1. The Stage to be performed by the System

\section{A. Preprocessing}

Preprocessing to Chrysanthemum image is done at this stage so that the image can be done by using an artificial neural network. The preprocessing process involves the cropping stage of the image to select an important part of the Chrysanthemum image. Then proceed with the resize image stage. The resize stage works to resize the image. In this study, the image was converted to a size of 50x50 pixels, so that the matrix obtained is not too much and accelerates the process of extraction of forms and training of artificial neural networks for form extraction. Stages of preprocessing the image can be seen in Fig. 2.

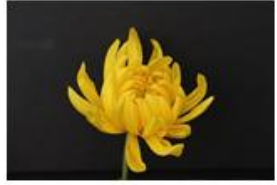

(A)

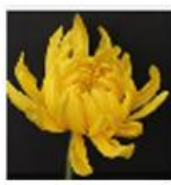

(B)

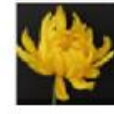

(C)
Fig. 2. Image Preprocessing: (A) Original Image. (B) Image of crop result. (C) Resized image with size 50x50 pixel.

\section{B. Sobel Edge Detection}

The image that has been through the preprocessing stage will then be processed again using edge detection Sobel. Edge detection aims to get a border so that the image is easily recognizable during the identification process using a backpropagation neural network. The image that is processed using Sobel edge detection will have a matrix of 1 and 0 , where 0 represents the background of the detected image and 1 represents the border of the detected object [2][8]. The shape extraction stage using the detection of the Sobel edge is shown in Fig. 3.
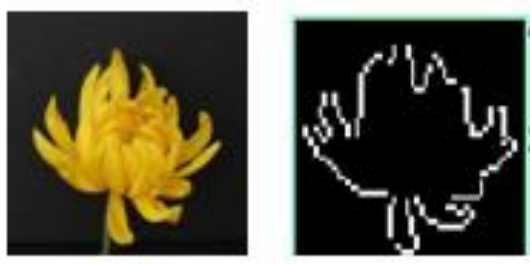

Fig. 3. Results of the Sobel Edge Detection Matrix

\section{Identification using Artificial Neural Networks}

The identification stage is the result of chrysanthemum identification by using artificial neural network method backpropagation[3][7][14]. The identification process is carried out by taking the value of the weight of the color extraction and the value of the extraction weight of the form as acomparison with the previously trained trainer data using artificial neural networks. The results of identification will appear in accordance with the training data if the value of the color extraction weight and extraction of the form close to or in accordance with the value of weight that exists in the data train. The page view of artificial neural network identification is shown in Fig. 4. 

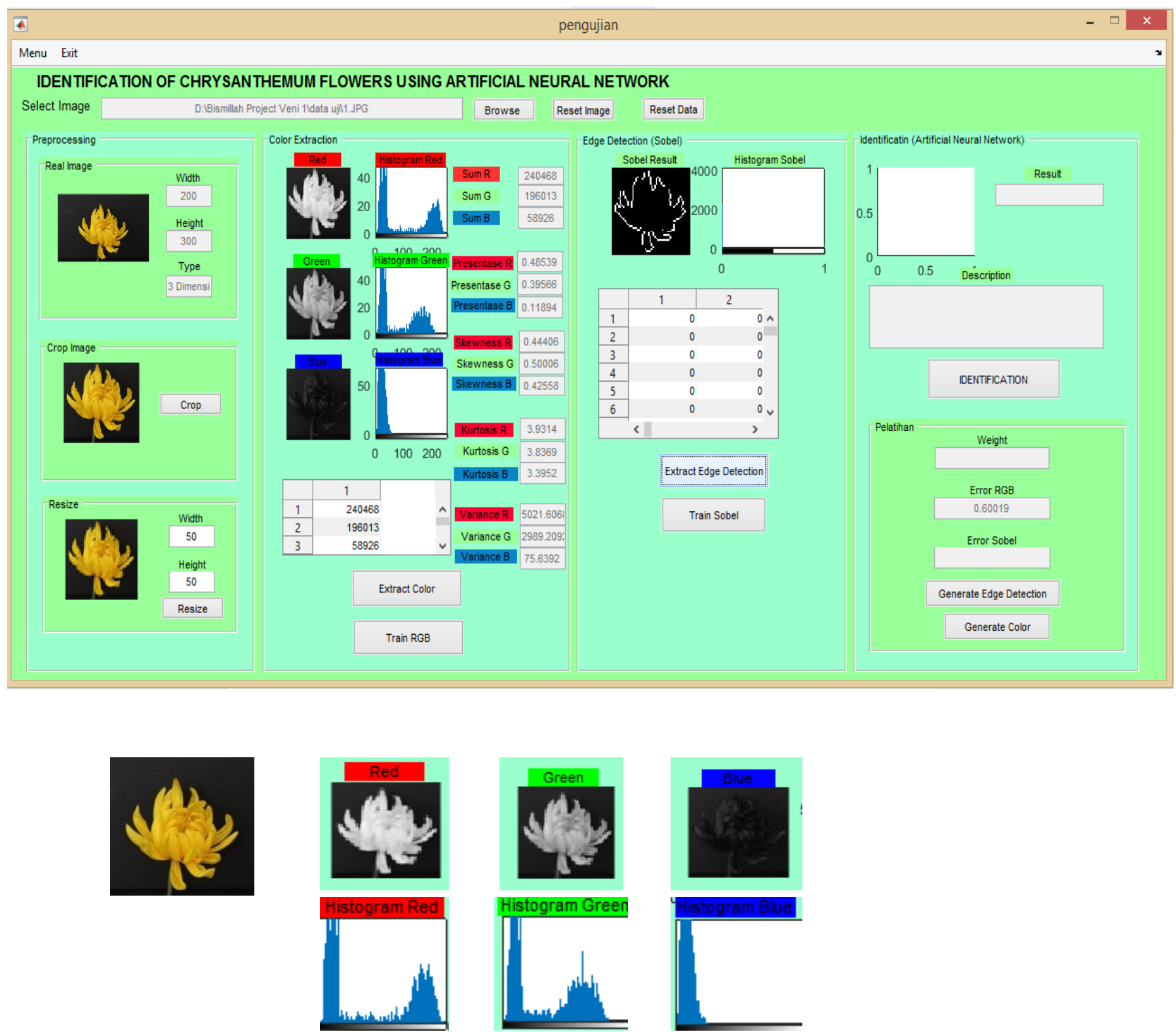

Fig. 4. Results of Artificial Neural Network Identification

Based on the image that has been entered as shown in Fig. 4 , the identification results are appropriate and produce a weight value of 0.179432 . The resulting weight value is a value that identifies the interest of chrysanthemum using artificial neural networks. In this study used sigmoid binary activation function that has a range of values between $0-1$. So that each weight value generated will be in the interval 0 1 .

\section{RESULT}

The steps taken in this research include the preprocessing phase which aims to crop and resize the image to be $50 \times 50$ pixels, the color extraction stage using RGB, the extraction stage of the shapes using edge detection Sobel, and stages of identification using the method artificial neural network backpropagation. RGB color extraction is done to extract the color of each type of interest to know its value to be the test target data. Similarly, the shape extraction uses a sobel edge

detection that serves to detect the edges of the already resized flowers and to obtain the matrix from the detection of the sobel edges as target data for testing. An artificial neural network with backpropagation method is used to identify the type of image that has been entered. Before the backpropagation network is determined, each network must be tested first by trial and error. This network experiment has a function to create artificial neural networks in accordance with the data to be trained and to create the network with the minimum error value so that errors at the time of testing will be smaller and greater accuracy. Here is a network testing experiment by searching for the smallest error value that can be seen in Table 1 and Table 2.

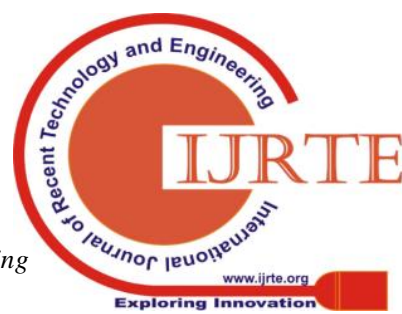




\section{Identification of Chrysanthemum Flower Based on Color and Flower Form Using Sobel Edge and ArtificialNeuralNetwork}

Table 1.Experiment Determination of RGB Color Extraction Network

\begin{tabular}{|c|c|c|c|c|c|c|c|c|c|c|c|}
\hline \multirow{2}{*}{ No } & \multirow{2}{*}{$\begin{array}{l}\text { Layer } \\
\text { Function }\end{array}$} & \multirow{2}{*}{$\begin{array}{c}\text { Learning } \\
\text { rate }\end{array}$} & \multirow{2}{*}{\multicolumn{2}{|c|}{\begin{tabular}{|l|}
$\begin{array}{l}\text { Perform. } \\
\text { function }\end{array}$ \\
MSE SSE \\
\end{tabular}}} & \multirow{2}{*}{ Epoch } & \multicolumn{2}{|c|}{$\begin{array}{c}\text { Param } \\
\text { goal }\end{array}$} & \multicolumn{3}{|c|}{ Error Value RGB } & \multirow{2}{*}{$\begin{array}{l}\text { Means } \\
\text { error } \\
\text { RGB }\end{array}$} \\
\hline & & & & & & 0.01 & \begin{tabular}{|l|}
0.005 \\
\end{tabular} & 1 & 2 & 3 & \\
\hline 1 & $\left.\begin{array}{ll}2 & 1\end{array}\right]$ & 0.1 & $\checkmark$ & & 2000 & $\checkmark$ & & 1.34 & 3.13 & 3.36 & 2.61 \\
\hline 2 & {$\left[\begin{array}{ll}2 & 1\end{array}\right]$} & 0.1 & & $\checkmark$ & 2000 & $\checkmark$ & & 6.25 & 6.25 & 4.37 & 5.62 \\
\hline 3 & {$\left[\begin{array}{lll}5 & 4 & 1\end{array}\right]$} & 0.1 & $\checkmark$ & & 2000 & $\checkmark$ & & 1.19 & 6.25 & 6.25 & 4.56 \\
\hline 4 & {$\left[\begin{array}{lll}5 & 4 & 1\end{array}\right]$} & 0.1 & & $\checkmark$ & 2000 & $\checkmark$ & & 6.25 & 0.58 & 6.25 & 5.36 \\
\hline 5 & {$\left[\begin{array}{lll}15 & 7 & 1\end{array}\right]$} & 0.1 & $\checkmark$ & & 2000 & $\checkmark$ & & 6.25 & 3.11 & 3.12 & 4.16 \\
\hline 6 & {$\left[\begin{array}{lll}15 & 7 & 1\end{array}\right]$} & 0.1 & & $\checkmark$ & 2000 & $\checkmark$ & & 6.25 & 0.85 & 3.09 & 3.39 \\
\hline 7 & {$\left[\begin{array}{lll}15 & 7 & 1\end{array}\right]$} & 0.00001 & $\checkmark$ & & 2000 & & $\checkmark$ & 1.81 & 2.38 & 3.19 & 2.46 \\
\hline 8 & {$\left[\begin{array}{lll}15 & 7 & 1\end{array}\right]$} & 0.00001 & & $\checkmark$ & 2000 & & $\checkmark$ & 6.25 & 0.29 & 6.25 & 4.26 \\
\hline 9 & {$\left[\begin{array}{lll}15 & 8 & 1\end{array}\right]$} & 0.00001 & $\checkmark$ & & 2000 & & $\checkmark$ & 0.49 & 0.42 & 0.24 & 0.38 \\
\hline 10 & {$\left[\begin{array}{lll}15 & 8 & 1\end{array}\right]$} & 0.00001 & & $\checkmark$ & 2000 & & $\checkmark$ & 3.12 & 0.32 & 1.20 & 1.55 \\
\hline 11 & {$\left[\begin{array}{lll}15 & 8 & 1\end{array}\right]$} & 0.00001 & $\checkmark$ & & 5000 & & $\checkmark$ & 0.25 & 0.45 & 0.25 & 0.31 \\
\hline 12 & {$\left[\begin{array}{lll}15 & 8 & 1\end{array}\right]$} & 0.00001 & & $\checkmark$ & 5000 & & $\checkmark$ & 3.11 & 3.12 & 6.25 & 4.16 \\
\hline
\end{tabular}

Table 2.Experiment Determination of Shape Extraction Network

\begin{tabular}{|c|c|c|c|c|c|c|c|c|c|c|c|}
\hline \multirow[t]{2}{*}{ No } & \multirow{2}{*}{$\begin{array}{l}\text { Layer } \\
\text { Function }\end{array}$} & \multirow{2}{*}{$\begin{array}{c}\text { Learning } \\
\text { rate }\end{array}$} & \multirow{2}{*}{\multicolumn{2}{|c|}{\begin{tabular}{|c|}
$\begin{array}{c}\text { Perform. } \\
\text { function }\end{array}$ \\
MSE
\end{tabular}}} & \multirow{2}{*}{ Epoch } & \multicolumn{2}{|c|}{$\begin{array}{c}\text { Param } \\
\text { goal }\end{array}$} & \multicolumn{3}{|c|}{ Error Value RGB } & \multirow{2}{*}{$\begin{array}{l}\text { Means } \\
\text { error } \\
\text { RGB }\end{array}$} \\
\hline & & & & & & 0.01 & 0.005 & 1 & 2 & 3 & \\
\hline 1 & {$\left[\begin{array}{ll}2 & 1\end{array}\right]$} & 0.1 & $\checkmark$ & & 2000 & $\checkmark$ & & 0.497 & 0.496 & 0.466 & 0.487 \\
\hline 2 & {$\left[\begin{array}{ll}2 & 1\end{array}\right]$} & 0.1 & & $\checkmark$ & 2000 & $\checkmark$ & & 0.005 & 0.005 & 0.004 & 0.004 \\
\hline 3 & {$\left[\begin{array}{lll}5 & 4 & 1\end{array}\right]$} & 0.1 & $\checkmark$ & & 2000 & $\checkmark$ & & 0.482 & 0.471 & 0.485 & 0.479 \\
\hline 4 & {$\left[\begin{array}{lll}5 & 4 & 1\end{array}\right]$} & 0.1 & & $\checkmark$ & 2000 & $\checkmark$ & & 0.005 & 0.005 & 0.004 & 0.005 \\
\hline 5 & & 0.1 & $\checkmark$ & & 2000 & $\checkmark$ & & 0.498 & 0.495 & 0.472 & 0.488 \\
\hline 6 & {$\left[\begin{array}{lll}15 & 7 & 1\end{array}\right]$} & 0.1 & & $\checkmark$ & 2000 & $\checkmark$ & & 0.487 & 0.005 & 0.005 & 0.005 \\
\hline 7 & {$\left[\begin{array}{lll}15 & 7 & 1\end{array}\right]$} & 0.00001 & $\checkmark$ & & 2000 & & $\checkmark$ & 0.002 & 0.478 & 0.471 & 0.479 \\
\hline 8 & {$\left[\begin{array}{lll}15 & 7 & 1\end{array}\right]$} & 0.00001 & & $\checkmark$ & 2000 & & $\checkmark$ & 0.241 & 0.002 & 0.002 & 0.002497 \\
\hline 9 & {$\left[\begin{array}{lll}15 & 8 & 1\end{array}\right]$} & 0.00001 & $\checkmark$ & & 2000 & & $\checkmark$ & 0.002 & 0.248 & 0.231 & 0.240 \\
\hline 10 & {$\left[\begin{array}{lll}15 & 8 & 1\end{array}\right]$} & 0.00001 & & $\checkmark$ & 2000 & & $\checkmark$ & 0.242 & 0.240 & 0.002 & 0.002497 \\
\hline 11 & {$\left[\begin{array}{lll}15 & 8 & 1\end{array}\right]$} & 0.00001 & $\checkmark$ & & 5000 & & $\checkmark$ & 0.002 & 0.002 & 0.241 & 0.241 \\
\hline 12 & {$\left[\begin{array}{lll}15 & 8 & 1\end{array}\right]$} & 0.00001 & & $\checkmark$ & 5000 & & $\checkmark$ & 3.11 & 3.12 & 0.002 & 0.00296 \\
\hline
\end{tabular}

Based on Table 1 it can be concluded that the determination of the backpropagation network for RGB color extraction with the minimum error value is experiment number 11 with the layer function [15 81 1] which means there are 15 inputs, 8 hidden layers, 1 output, learning rate of 0.00001, performance function MSE (Mean Squared Error), epoch or iteration as much as 5000 times, the goal parameter is 0.005 , resulting in an average RGB error in 0.31 . Determination of the backpropagation network with the minimum error value for the extraction of the shapes using the detection of the Sobel edge based on table 2 was found in the 12th experiment with the layer function [15 8 1] where there were 15 inputs, 8 hidden layers, and 1 output, learning rate of 0.00001 , performance function using SSE (Sum Squared Error), epoch as much as 5000 times, parameter of goal equal to 0.005 , which resulted in an average error value of equal to 0.002496 . The target value range is obtained by looking at the average value of the last weights of each of the training data [10]. The result of the target value can be seen in Table 3 .

Table 3. Target Value of the training data

\begin{tabular}{|c|l|c|c|}
\hline No & Flower & Target Value & Range Target Value \\
\hline 1 & Irana & 0 & $0-0.2$ \\
\hline 2 & Vania & 0.25 & $0.21-0.50$ \\
\hline 3 & Pink Standard & 0.50 & $0.51-0.60$ \\
\hline 4 & White Puma & 0.75 & $0.61-0.80$ \\
\hline 5 & Purple Aster & 1 & $<=1$ \\
\hline
\end{tabular}

Validation trials are performed by comparing the results of the training data with test data. To calculate the level of accuracy of testing used Confusion Matrix, but also conducted the exchange of training data with test data using the K Fold Cross Validation so that the test data into the amount of 100 data chrysanthemum image. In addition, validation testing is also performed on data by using only feature extraction, color and or use characteristic shape extraction. For test data, test using only color extraction or form extraction alone is not exchanged data with $\mathrm{K}$ Fold Cross Validation so that the amount of test data used amounted 50 data. The trials were also performed using the extraction of flower color features and disc flower sections or basic dishes of chrysanthemum flowers. Picture of flower and flower disk can be seen in Fig. 5. Result of validation can be seen in Table 4.

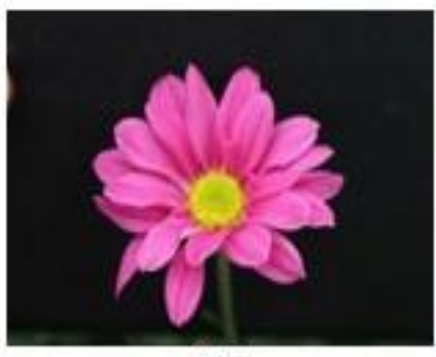

(A)

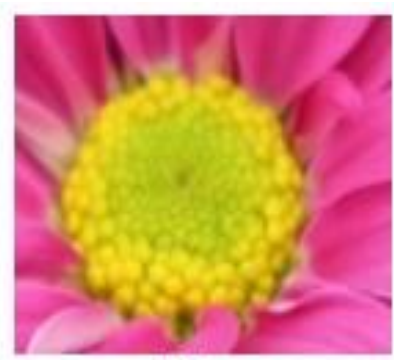

(B)
Fig. 5. Chrysanthemum Part. (A). Flower. (B) Flower Disk or Basic Chrysanthemum Flower

Table 4.Result of test validation

\begin{tabular}{|c|l|c|}
\hline No & Test Validation & $\begin{array}{c}\text { Accuration } \\
(\%)\end{array}$ \\
\hline 1 & Identification by Color Extraction and Form Extraction & 65.36 \\
\hline 2 & Identify by Color Extraction on Interest & 75.35 \\
\hline 3 & $\begin{array}{l}\text { Identification bay Color Extraction on Flowers and Basic } \\
\text { Flower Plates }\end{array}$ & 69.44 \\
\hline 4 & Identification with Form Extraction (Sobel) & 59.52 \\
\hline
\end{tabular}

\section{CONCLUSION}

This study aims to identify chrysanthemum flowers using artificial neural networks with the extraction of Red, Green, and Blue color features. The activation function used in color feature extraction is binary sigmoid (logsig), layer function [15 8 1], the learning rate of 0.00001 , MSE performance function (Mean Squared Error), and epoch 5000 times. As for the training of artificial neural networks for the extraction of forms using sobel edge, detection used sigmoid binary activation function (logsig), layer function [15 81 1], the learning rate of 0.00001 , performance function SSE (Sum Squared Error), and epoch 5000 times. The chrysanthemum identification process using artificial neural network backpropagation was done with four types of trials consisting of the first test using RGB color extraction and form extraction with accuracy result of $65.36 \%$, second test using color extraction with accuracy result equal to $75.35 \%$, $u$ The third try uses color extraction on two flower parts i.e. flower disk and overall flower with $69.44 \%$ accuracy, and the fourth test uses form extraction with accuracy result of $59.52 \%$.

\section{REFERENCES}

1. Agmalaro M.A., Kustiyo A.andAkbar A. "Identifikasi Tanaman Buah Tropika Berdasarkan Tekstur Permukaan Daun Menggunakan Jaringan Syaraf Tiruan."Jurnal Ilmu Komputer dan Agri-Informatika, vol. 2, no. 2,pp. 73-82, 2013.

2. DudaRO, Hart PE. 1995. Pattern Classificationand Scene Analysis2 ${ }^{\text {nd }}$ edition. New York: John Wiley \& Sons.Inc.

3. Fausett L. 1994. Fundamentals of Neural Networks (Architectures, Algorithms, and Applications). New Jersey : Prentice-Hall, Inc.

4. Gonzalez R.C. and Woods R.E.Digital Image Processing, New Jersey: Prentice Hall, 2002. 
5. Ichsani U.N., Triyanto D and Ruslianto I. "Klasifikasi Jenis Bunga Kamboja Jepang (Adenium Sp.) Berdasarkan Citra Mahkota

MenggunakanEkstraksiFiturWarna dan Deteksi Tepi." Coding Jurnal Komputer dan Aplikasi, vol. 3, no. 3, pp. 1-12, 2015.

6. Irianto S.Y., Analisa Citra Digital dan Content Based Image Retrieval, Lampung : AURA., 2016.

7. Kusumadewi Sri. Artficial Intelligence (Teknik dan Aplikasinya). Jakarta: Graha Ilmu, 2003.

8. McAndrew A. 2004. An Introduction to Digital Image Processing with Matlab. Australia: Thomson.

9. Muwardi F and A. Fadlil. "Sistem Pengenalan Bunga Berbasis Pengolahan Citra dan Pengklasifikasi Jarak,"Jurnal Ilmu Teknik Elektro Komputer dan Informatika, vol. 3, no. 2, pp. 124-131, 2017.

10. Qur'ania A. and Sarinah I. Identification of Jasmine Flower (Jasminum sp.) Based on the Shape of the Flower using Sobel Edge and $k$-Nearest Neighbor.IOP Conf. Series: Materials Science and $\begin{array}{llll}\text { Engineering } & 332 & \text { (2018) }\end{array}$ doi:10.1088/1757-899X/332/1/012008

11. Rukmana R.andMulyana, A.E. Budidaya Krisan. Yogyakarta: Kanisius, 1997.

12. Salinger, J.P. 1985. Commercial Flower Growing Butterworths of New Zealand.

13. Siraj F.H., M. Ekhsan and A. N. Zulkifli, "Flower Image Classification Modeling Using Neural Network." In International Conference on Computer, Control, Informatics and Its Applications. pp. 81-86, 2014

14. Wu SG et al. 2007. A Leaf RecognitionAlgorithm for Plant Classification usingProbabilistic Neural Network. China: Chinese Academy of Science. 